\title{
PENGARUH NILAI WETTABILITY PADA POOL BOILING HEAT TRANSFER STUDI KASUS HYDROPHOBIC, HYDROPHILIC DAN SUPERHYDROPHILIC
}

\author{
BAMBANG JOKO SUROTO* \\ Departemen Fisika Fakultas MIPA Universitas Padjadjaran, \\ Jl. Raya Bandung-Sumedang Km 21, Jatinangor 45363 \\ *email : bambang.joko@unpad.ac.id
}

\begin{abstract}
Abstrak. Telah dilakukan penelitian tentang efek dari berbagai nilai wettability dari permukaan pada pool boiling heat transfer. Percobaan dilakukan dengan menggunakan air murni sebagai fluida kerja dan subcooling 0K. Heat transfer block yang digunakan adalah mirror surafce (dipoles tembaga) / hidrofilik, superhydrophilic / copper berlapis $\mathrm{TiO} 2$ and permukaan hidrofobik / PTFE. Hasil penelitian menunjukkan bahwa kinerja perpindahan panas dari permukaan dengan lapisan PTFE lebih baik di fluks panas rendah. Sedangkan untuk fluks panas menengah, permukaan superhydrophilic (TiO2) lebih unggul dibandingkan dengan permukaan hidrofilik dan hidrofobik.
\end{abstract}

Kata kunci : Wettability, subcooling, super/hydrophilic, superhydrophilic, boiling

\begin{abstract}
The effect of varying surface wettabilities on nucleate pool boiling heat transfer has been examined and investigated. The experiments were performed using pure water as the working fluid and subcooling $0 \mathrm{~K}$. The heat transfer block used were bare surface/hydrophilic (polished copper), superhydrophilic/TiO2-coated copperand hydrophobic/PTFE surface. The results showed that the heat transfer performance of surfaces with PTFE coating is better at low heat flux. While for intermediate heat flux, superhydrophilic surface ( $\mathrm{TiO} 2)$ is superior compared to hydrophilic and hydrophobic surfaces.
\end{abstract}

Keywords : Wettability, subcooling, super/hydrophilic, superhydrophilic, boiling

\section{Nomenclature}

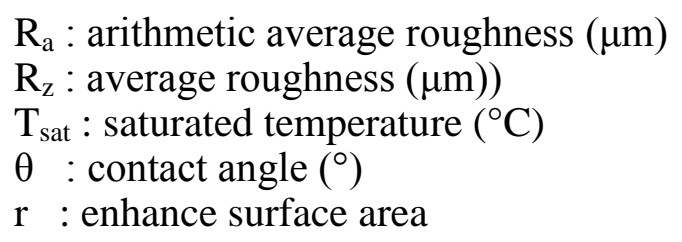

\section{Pendahuluan}

Secara umum, keterbasahan permukaan dapat diklasifikasikan ke dalam dua istilah, tergantung pada nilai sudut kontak, yaitu hidrofilik dan hidrofobik seperti yang ditunjukkan pada Gambar 1. (a) dan (b), masing-masing. Bahan seperti titanium dioksida $\left(\mathrm{TiO}_{2}\right)$ di bawah sinar UV menunjukkan sudut kontak yang sangat kecil (hampir 0 derajat) seperti dilansir Takata et al. [1]. Efek ini disebut foto-induced superhydrophilicity dan sudut kontak mencapai mendekati nol ketika permukaan terkena sinar UV, seperti yang ditunjukkan pada Gambar 1. (a). Sudut kontak nol merupakan indikasi bahwa permukaan memiliki afinitas tertinggi 
dengan cairan. Pada saat yang sama, hidrofilik diwakili oleh sudut kontak $5^{\circ}<\theta$ $<90^{\circ}$.

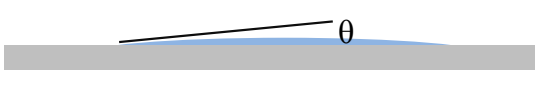

$\theta<5^{\circ}$

(a) Superhydrophilic

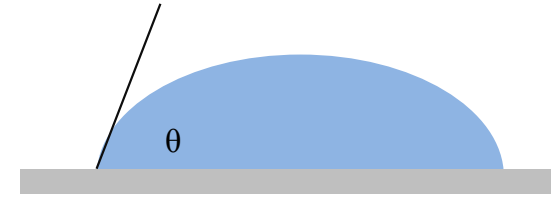

$5^{\circ}<\theta<90^{\circ}$

(b) Hydrophilic

Gambar 1. Contact angle dari superhydrophilic and hydrophilic

Jelas wettability dipengaruhi oleh kekasaran dan menarik bagaimana ketergantungan keterbasahan pada nilai kekasaran dapat diukur. Gambar 2. menunjukkan hubungan antara kemampuan kebasahan dan nilai kekasaran. Kubiak et.al memodelkan dengan menggunakan kombinasi dari persamaan Wenzel dan Casie-Bexter dan juga digunakan morfologi 2D permukaan [2]. Meskipun sample uji memiliki nilai kekasaran yang sama, itu tidak berarti bahwa bahan akan memiliki sudut kontak yang sama. Garis merah vertikal di Gambar 2. menunjukkan nilai kekasaran 0,6 $\mu \mathrm{m}$, namun, sudut kontak sekitar $25^{\circ}$ untuk PMMA dan $65^{\circ}$ untuk paduan tembaga dan keramik, masing-masing.

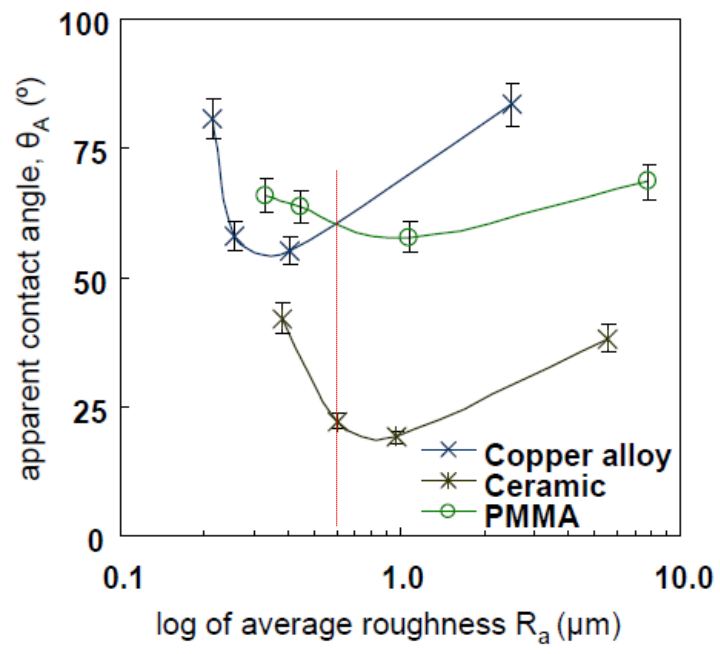

Gambar 2. Contact angle and variasi nilai roughness dari copper, ceramic and PMMA[2]

\section{Metode Penelitian}

Gambar 3. menunjukkan skema dari fasilitas eksperimental. Vessel terdiri dari sebuah silinder kaca (2) dengan inner-diameter $120 \mathrm{~mm}$ dan kotak-kaca sdengan yang dicasing sebagai isolator panas (3). Untuk mempertahankan suhu liquid/working fluid kita menggunakan pemanas udara (8). Suhu dikontrol \pm $0.1 \mathrm{~K}$ oleh pemanas (5) dan kondensor (4). Pada saat yang sama, temperature direkam menggunakan tiga termokopel (6) dan pengukuran dilakukan dalam kondisi steady state. Dinamika gelembung seperti gelembung lahirnya dan 
frekuensi gelembung keberangkatan dianalisis menggunakan kamera kecepatan tinggi (9) dan kamera video (10).
1. Heating Surface
2. Boiling Vessel
3. Insulation material
4. Condenser
5. Heater
6. Thermocouple
7. Heater
8. Air Heater
9. Video Camera
10. High Speed Camera

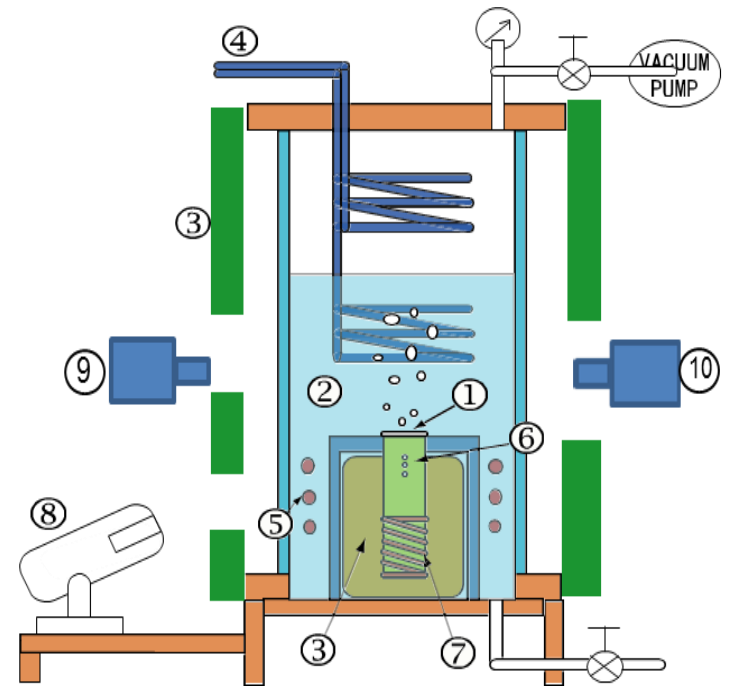

Gambar 3. Contact angle dari superhydrophilic and hydrophilic

Selanjutnya, setelah sampel permukaan diinstal, air dibuang dari vessel. Tujuan kedua memompa udara dari vessel adalah untuk memeriksa apakah ada kebocoran udara dari sistem. Kebocoran diperiksa dengan indikasi dari sensor tekanan. Langkah berikutnya adalah untuk mengisi air suling ke vessel. Pastika bahwa volume air suling adalah $90 \%$ dari volume vessel sehingga menenggelamkan pemanas. Setelah semua proses telah dilakukan, panaskan selama 30 menit untuk proses degassing.

Heat transfer block ( sample uji) adalah silinder tembaga. Sample uji menghadap ke atas dan dilengkapi dengan sirip dekat tepi untuk mencegah bubble nukleasi dipinggir sample uji. Detail permukaan sample uji ditunjukkan pada Gambar 2.2. Permukaan sample memiliki permukaan utama dengan diameter $30 \mathrm{~mm}$, panjang $100 \mathrm{~mm}$ dan ketebalan sirip 0,3 mm. Termokopel diposisikan pada 3,8 dan 13 $\mathrm{mm}$ dari permukaan, masing-masing.

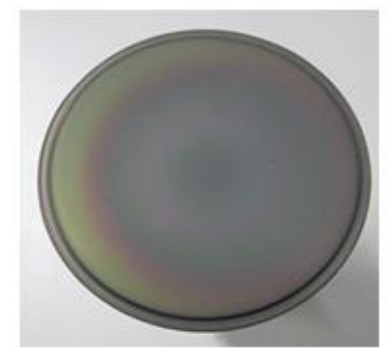

a. $\mathrm{TiO}_{2}$ surface

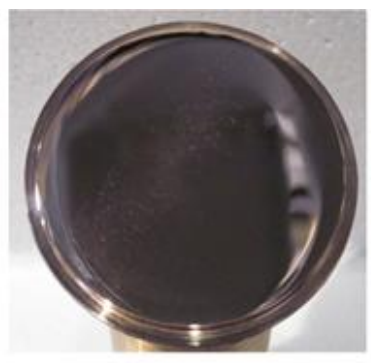

b. Copper surface

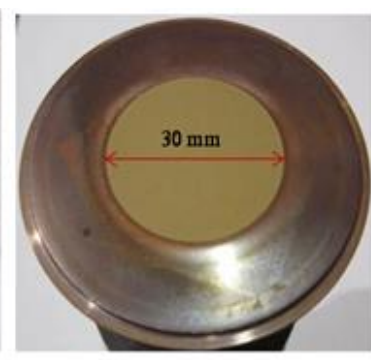

c. PTFE surface

Gambar 3. Sample yang diuji $\mathrm{TiO}_{2}$ (superhydrophilic), polished-copper (hydrophilic) dan PTFE (hydrophobic) 


\section{Hasil dan Pembahasan}

Gambar 4. menunjukkan boiling-curve dari tiga sample uji, yaitu permukaan dipoles-tembaga (hydrophilic), permukaan PTFE (hydrofobik) dan permukaan $\mathrm{TiO}_{2}$ (superhydrophilic). Penurunan kinerja permukaan PTFE adalah karena seluruh permukaan PTFE ditutupi oleh kubah gelembung saat superheating lebih tinggi dari $18 \mathrm{~K}$. Tabel 1 menunjukkan sifat-sifat fisik dari permukaan sampel, yaitu kekasaran permukaan, $\mathrm{R}_{\mathrm{a}} / \mathrm{R}_{\mathrm{z}}$, sudut kontak, $\theta$, dan peningkatan luas permukaan, r. Data yang disajikan dalam Tabel 1. membantu kita untuk menjawab mengapa permukaan $\mathrm{TiO}_{2}$ unggul dalam segala kondisi dengan permukaan dipoles-tembaga. Pada saat yang sama, kurva didih permukaan $\mathrm{TiO}_{2}$ hampir bertepatan dengan permukaan PTFE ketika superheating bawah $10 \mathrm{~K}$. Permukaan $\mathrm{TiO}_{2}$ memiliki kekasaran, $\mathrm{R}_{\mathrm{a}}=0.568 \mu \mathrm{m}$ dan peningkatan luas permukaan, $\mathrm{r}=$ 2,077, dibandingkan dengan permukaan PTFE dengan $\mathrm{R}_{\mathrm{a}}=0.980 \mu \mathrm{m}$ dan $\mathrm{r}=$ 1,619. Nilai kekasaran, $R_{a}$, permukaan $\mathrm{TiO}_{2}$ lebih rendah, namun, nilai dari pertambahan luas permukaan, r, lebih tinggi dari permukaan PTFE. Hal ini diketahui, bahwa kekasaran permukaan meningkatkan performa dari boiling heat transfer $[3,4]$. Nilai kekasaran tinggi dikaitkan dengan yang lebih besar cavitydiameter yang berpotensi menjadi situs gelembung nukleasi. Permukaan dipolestembaga menunjukkan kinerja buruk karena nilai kekasaran, $R_{a}$, yang lebih rendah dibandingkan dengan permukaan $\mathrm{TiO}_{2}$ dan PTFE. Ketidakliniaran antara kekasaran permukaan dan sudut kontak pada Tabel 1. adalah sesuai dengan hasil yang diperoleh oleh Kubiak et al. [2].

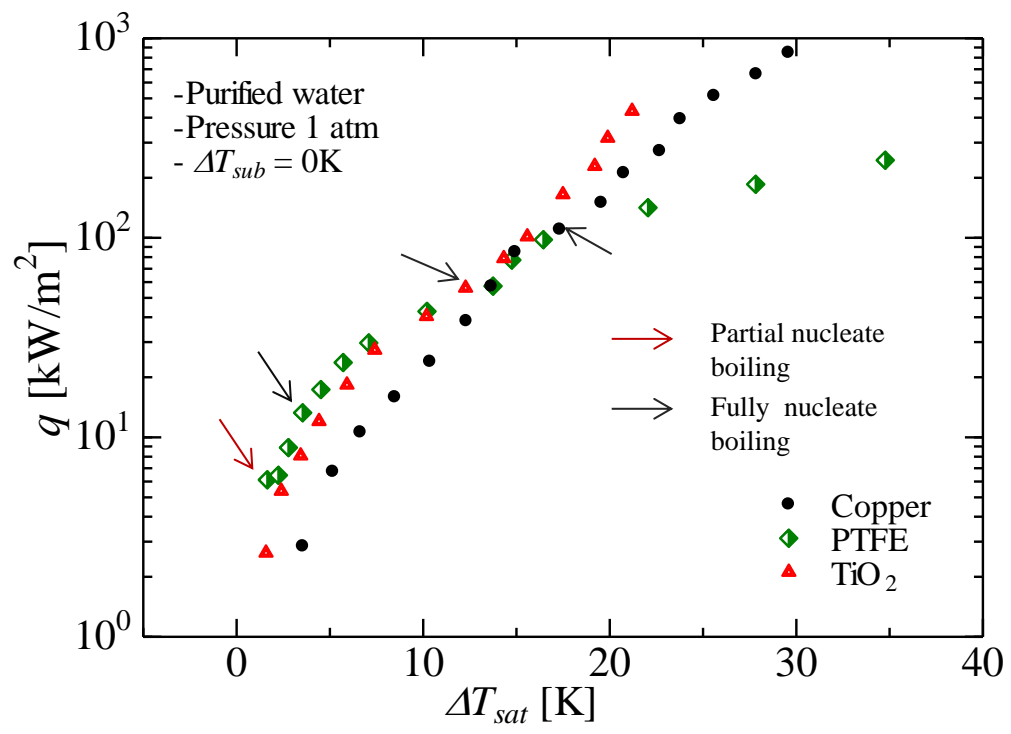

Gambar 4. Boiling-curve dari copper, PTFE dan $\mathrm{TiO}_{2}$

Grafik boiling-curve menunjukkan bahwa peningkatan sudut kontak dari $\theta=0^{\circ}$ $\left(\mathrm{TiO}_{2}\right)$ ke $\theta=70^{\circ}$ (permukaan dipoles-tembaga) tidak linear dengan peningkatan performa perpindahan panas. Analisis performa dari boiling heat transfer dimulai dari permukaan dipoles-tembaga dan $\mathrm{TiO}_{2}$. Permukaan $\mathrm{TiO}_{2}$ menunjukkan kinerja yang lebih baik dibandingkan dengan permukaan dipoles-tembaga untuk semua kondisi, seperti yang ditunjukkan pada Gambar 4. Namun, pada $\Delta \mathrm{T}_{\text {sat }}=18 \mathrm{~K}$ 
sample $\mathrm{TiO}_{2}$ dan permukaan dipoles-tembaga bertemu dan kemudian berpisah sesudahnya. Pada saat yang sama, karakteristik unik ditunjukkan pada Gambar 4. dimana ketika $\Delta \mathrm{T}_{\text {sat }}>18 \mathrm{~K}$ menjadi titik persimpangan dari tiga sampel. Permukaan PTFE menunjukkan penurunan kinerja sedangkan permukaan $\mathrm{TiO}_{2}$ tetap superior dibandingkan dengan dua sampel lainnya.

Tabel 1. Physical properties dari copper, PTFE dan TiO2

\begin{tabular}{|c|c|c|c|c|}
\hline Sample surface & $R_{\mathrm{a}}$ & $R z$ & Contact angle $(\theta)$ & $\begin{array}{c}\text { Enhancement of } \\
\text { surface area }(r)\end{array}$ \\
\hline Polished copper & 0.007 & 0.045 & $66^{\circ}-70^{\circ}$ & 1.009 \\
\hline $\mathrm{TiO}_{2}$ & 0.568 & 5.564 & $\simeq 0^{\circ}$ & 2.077 \\
\hline PTFE & 0.980 & 11.540 & $120^{\circ}-130^{\circ}$ & 1.619 \\
\hline
\end{tabular}

\section{Kesimpulan}

Penelitian efek wettability terhadap boiling heat transfer telah dilakukan dengan menggunakan tiga bahan, yaitu permukaan, hidrofobik, hidrofilik dan superhidrophilik. Hasilnya sebagai berikut:

1. Permukaan hidrofilik memiliki kinerja perpindahan panas didih terendah dibandingkan dengan superhydrophilic dan permukaan hidrofobik.

2. Permukaan hidrofobik menunjukkan keunggulannya pada fluks panas rendah, namun, pada fluks panas tinggi kinerja menurun.

3. Permukaan superhidrophilik menunjukkan keunggulannya dari fluks panas menengah ke tinggi dibandingkan dengan permukaan hidrofilik dan hidrofobik.

\section{Daftar Pustaka}

1. Takata, Y., Hidaka, S., Masuda, M., and Ito, T., Pool Boiling on a Superhydrophilic Surface, Int. J. Energy Res. 27 (2003) 111-119.

2. Kubiak, K.J., Wilson, M.C.T., Mathia, T.G., and Carval, Ph., Wettability versus roughness of engineering surfaces, Wear 271 (2011) 523-528.

3. Phan, H.P., Caney, N., Marty, P., Colasson, S., and Gavillet, J., Surface Wettability Control by Nanocoating: The Effects on Pool Boiling Heat Transfer and Nucleation Mechanism, International Journal of Heat and Mass Transfer 52 (2009) 5459-5471.

4. Pioro, I.L., Rohsenow, W., Doerffer,.S.S., Nucleate pool-boiling heat transfer . I: review of parametric effects of boiling surface, International Journal of Heat and Mass Transfer 47 (2004) 5033-5044 